\title{
DIALOGISMO E INTERTEXTUALIDADE: UMA LEITURA DE ELEMENTOS RELIGIOSOS NO BIG BROTHER BRASIL 2009
}

\author{
Amanda Marciniak Martins ${ }^{1}$ \\ Gabriela Marçal Gobi ${ }^{2}$ \\ Rafaela Mariane M. Cândido ${ }^{3}$ \\ Marcelo Fernando de Lima ${ }^{4}$
}

\section{Resumo}

O objetivo deste trabalho é analisar o uso de intertextualidade e dialogismo de textos religiosos no reality show Big Brother Brasil, em sua nona edição, de 2009. Com o estudo, pretendemos mostrar que as referências religiosas presentes no reality show são um possível recurso para aumentar a audiência.

Palavras-chave: Televisão, religião, intertextualidade, dialogismo.

\begin{abstract}
The aim of this article is to analyze the use of intertextuality and dialogism in religious texts in the $9^{\text {th }}$ edition of Big Brother Brazil (2009). With this work, we tried to demonstrate that religious references are used in the reality show possibly to reach bigger audiences.

Keywords: Television, religion, intertextuality, dialogism.
\end{abstract}

\section{Introdução}

Este trabalho tem por objetivo refletir sobre os usos da intertextualidade e do dialogismo a partir da análise de episódios da nona edição do reality show Big Brother Brasil, de 2009. Os princípios teóricos que norteiam este trabalho discutem o dialogismo como um elemento constitutivo da linguagem.

Em nosso embasamento, fizemos um breve percurso dos conceitos de heterogeneidade, polifonia, dialogismo, intertextualidade e interdiscursividade. Em seguida, apresentamos a religião como objeto de interesse da mídia televisiva brasileira. Por fim, realizamos a identificação e análises de cenas e imagens que foram veiculadas no programa.

\footnotetext{
${ }^{1}$ Graduada em Comunicação Institucional na Universidade Tecnológica Federal do Paraná (UTFPR).

${ }^{2}$ Graduada em Comunicação Institucional na Universidade Tecnológica Federal do Paraná (UTFPR).

${ }^{3}$ Graduada em Comunicação Institucional na Universidade Tecnológica Federal do Paraná (UTFPR).

${ }^{4}$ Jornalista, doutor em Letras (Universidade Federal do Paraná) e professor-adjunto da UTFPR. Orientador da pesquisa sobre os elementos religiosos no Big Brother Brasil.
} 


\title{
Mídia televisiva brasileira e religião
}

A religião é parte do cotidiano no Brasil. Em 2000, a população brasileira era em sua maior parte católica, época de início do Big Brother Brasil (2002). Já em 2010, 86,8\% eram cristãos: $64,6 \%$ católicos e $22,2 \%$ evangélicos (IBGE). ${ }^{5}$

Os elementos religiosos encontrados nos textos e no discurso do BBB são predominantemente da cultura cristã, que tem como base a Bíblia. As religiões que a utilizam e que possuem maior número de fiéis no Brasil são as seguintes ${ }^{6}$ :

\begin{tabular}{|l|l|l|} 
Ano & 2000 & 2010 \\
\hline Católica & 124.980 .132 & 123.280 .172 \\
\hline Evangélica & 26.184 .941 & 42.275 .440 \\
\hline Espírita & 2.262 .401 & 3.848 .876 \\
\hline Sem religião & 12.876 .356 & 15.335 .510 \\
\hline
\end{tabular}

Há duas décadas, os evangélicos pentecostais vêm despertando o interesse de vários segmentos da sociedade. Para Freston (1993, p.44), eles têm por princípio religioso a divulgação de sua fé, sobretudo pelos meios de comunicação massivos. Na Rede Record, por exemplo, a exploração desse fator é constante. Em 1989, a Igreja Universal do Reino de Deus (IURD) adquiriu a Record, tornando-se a primeira igreja evangélica a ser proprietária de uma televisão com cobertura nacional.

Alberto Klein (2006, p.144) chega a afirmar que a relação criada entre a mídia e o sagrado acaba sacralizando e favorecendo a própria mídia. Um exemplo apontado pelo autor são as sessões de cura por meio da fé:

\begin{abstract}
A crescente presença de programas religiosos no rádio e na televisão pode ser vista como fruto da união do ímpeto missionário cristão com o poder irradiador dos meios eletrônicos. Estes proporcionariam, com menos esforço, a possibilidade de acelerar a ordem de ir e fazer discípulos em todas as nações. Em um mundo midiático, fazer missões deixa de ser uma atividade exclusiva de um corpo que se inscreve em um determinado espaço, em uma determinada cultura, com a finalidade de levar o evangelho, muitas vezes em espaços hostis, com todos os riscos assumidos (KLEIN, 2006, p. 144).
\end{abstract}

Ou seja, o trabalho de difundir a fé vem aumentando consideravelmente no território brasileiro, fruto da união entre mídia e religião. Conforme Lenildo Campos (1988, p. 23), trabalhando com a trilogia fé, salvação e cura, e vendendo a salvação, os televangelistas

\footnotetext{
${ }^{5}$ Disponível em: http://veja.abril.com.br/blog/reinaldo/geral/o-ibge-e-a-religiao-\%E2\%80\%93-cristaos-sao-868do-brasil-catolicos-caem-para-646-evangelicos-ja-sao-222/. Acessado em 01/12/13.

${ }^{6}$ Disponível em: http://seriesestatisticas.ibge.gov.br/series.aspx?vcodigo=POP60. Acessado em: 03/01/2014.
} 
garantem na TV a cura de doenças dentro de estratégias de marketing que visam atingir um maior número de fiéis.

Porém, é importante enfatizar que o Brasil é um país que conta com uma vasta diversidade religiosa. Por possuir um estado laico, que tem como princípio a imparcialidade em assuntos religiosos, o Brasil apresenta liberdade de culto religioso e também a separação entre Estado e Igreja. Apesar disso, há preconceito contra algumas religiões e uma pressão atual para a formação de um estado cada vez mais influenciado por ideias religiosas.

\section{O percurso do Big Brother Brasil}

Os programas de reality shows passaram a ter sucesso na televisão brasileira a partir do ano 2000, com No Limite, Big Brother Brasil e Casa dos Artistas, sendo vistos por milhões de telespectadores. Fenômeno de sucesso relativamente recente na TV, os realities não são, apesar disso, uma novidade. Eles surgiram de forma embrionária na década de 1970. No Brasil, começou com No Limite, em 2000. Um ano depois, foi criada a Casa dos Artistas, que alavancou a audiência do SBT. Em 2002, surgiu o maior expoente deste gênero, o Big Brother Brasil. Posteriormente, em 2009, a TV Record lançou A Fazenda, versão brasileira de The Farm.

$\mathrm{O}$ BBB dura cerca de três meses, é transmitido à noite pela Rede Globo, todos os dias da semana após a novela, iniciando mais ou menos às 22 horas. Aos domingos, vai ao ar depois do Fantástico. As gravações ao vivo contam com a presença do apresentador Pedro Bial, e estas acontecem geralmente nos domingos, terças e quintas.

$\mathrm{O}$ BBB e outros programas de reality show surgiram numa época em que TVs no mundo todo passaram a dar maior espaço ao entretenimento. Para Lazary e Rodrigues (2011, p.25), ao assistir o BBB, o público ganha divertimento que interage com as emoções, assim como o futebol, a telenovela ou uma peça teatral. Em geral, o público se comove, envolve-se e projeta expectativas.

\section{Dialogismo e intertextualidade}

Antes de iniciar a descrição do conceito de dialogismo, Bakhtin (1992, p.163) explica que o diálogo pode ser definido como "toda comunicação verbal, de qualquer tipo que seja". Mas para compreender o conceito bakhtiniano de dialogismo, é necessário entender ainda que todo discurso é construído a partir de algo já existente, que é o “já dito”. Bakhtin (1992, p.150) 
afirma que o dialogismo é o processo de interação entre textos, tanto na polifonia, quanto escrita ou na leitura, isto é, o texto não é visto de maneira isolada.

Para Paulo Bezerra (2013, p.195), a polifonia e o dialogismo estão interligados a raízes amplas e multifacetadas. A polifonia se define pela interação em um mesmo espaço, com uma multiplicidade de vozes e consciência independentes:

[...] essas vozes e consciências não são objetos do discurso do autor, são sujeitos de seus próprios discursos. A consciência do personagem é a consciência do outro, não se objetifica, não se torna objeto da consciência do autor, não se fecha, está sempre aberta à interação com a minha e com as outras consciências e só nessa interação revela e mantém sua individualidade. Essas vozes possuem independência excepcional na estrutura da obra, é como se soassem ao lado da palavra do autor, combina-se com ela e com as vozes de outros personagens (2013, p. 195).

O autor apresenta neste trecho a voz do sujeito destinador ou enunciador e também a recepção do sujeito destinatário ou enunciatário. Sobre isso, Milton José Pinto (2002, p.12) explica que os participantes desta ação estão assujeitados às condições do contexto e passam a ser agentes de ações de produção, circulação e consumo de textos ou discursos.

Desta forma, é possível perceber no programa objeto de análise que o destinador (programa) promove imagens empíricas (elementos religiosos) ao transmitir a mensagem a seu público-alvo. Continuando ainda sobre a noção de dialogismo, Beth Brait e Rosineide de Melo (2007, p. 65) afirmam que é necessário compreender as noções e diferenciações entre enunciado e enunciação.

Segundo Brait e Melo (2005, p.63), o enunciado é a unidade real da comunicação discursiva. Todas as esferas da atividade humana estão relacionadas com o uso da língua que se evidencia em forma de enunciados (orais e escritos) concretos e singulares. Esses enunciados refletem as situações específicas nas esferas da atividade humana, não só pelo seu conteúdo (temático) e pelo seu estilo verbal (seleção de recursos lexicais, fraseológicos e gramaticais da língua), mas também, principalmente, pela sua organização composicional.

Já a enunciação, segundo Bakhtin (1992, p.93), é o produto da interação de dois indivíduos socialmente organizados, pois sua natureza é social. A enunciação não existe fora de um contexto sócio ideológico, em que cada locutor tem um "horizonte social" bem definido. Portanto, a enunciação procede de alguém e se destina a alguém. Qualquer enunciação propõe uma réplica, uma reação.

Conforme Bakhtin (1992, p.93), o locutor usa situações reais da fala para se comunicar, é a fonte do discurso, porém não é o autor porque em sua mensagem estão atribuídas narrativas 
que podem ser de sujeitos de consciências distintas do locutor. Esses indivíduos que participam da enunciação são definidos como sujeitos, de acordo com Helena Nagamine Brandão (2013, p.18). O sujeito é marcado pela sua historicidade, que se preocupa com o estudo da semântica em condições de verdade, denominado vericondicionalidade. Este "sujeito é situado no contexto sócio-histórico de uma sociedade em um espaço e tempo determinados e é repreendido por uma ideologia que reflete crenças, valores e princípios de um grupo social" (BRANDÃO, 2013, p. 26).

De acordo com Fiorin (2006, p.18), o dialogismo considera a realidade dos processos enunciativos. Nele, as construções do enunciado não são somente as reproduções sociais da forma estática do discurso; o enunciado é sempre ancorado pela heterogeneidade, porque revela duas posições: a sua e o seu avesso. O enunciado é parte constitutiva do diálogo e, diferentemente das unidades da língua como os sons, as palavras e as orações, é exclusivo, dependendo exclusivamente do produtor do discurso. Neste caso, ocorre a constituição de diferentes posições sociais que levarão à contradição, ou seja, no mínimo duas vozes aparecem nas relações dialógicas envoltas nas esferas individuais e sociais.

\section{Intertextualidade}

Fiorin propõe que a intertextualidade não possui o mesmo conceito de dialogismo. Na verdade, ela é um tipo de dialogismo, “aquele em que há no interior do texto o encontro de duas materialidades linguísticas, de dois textos. Para que isso ocorra, é preciso que um texto tenha existência independente do texto que com ele dialoga" (2006, p.52). Kristeva (2005, p.68) afirma que a intertextualidade pode ser compreendida como um diálogo entre textos: "todo texto se constrói como mosaico de citações, todo texto é absorção e transformação de um outro texto", isto é, não há texto neutro ou original, todo texto remete a outros já existentes.

Ao falarmos de intertextualidade, é necessário perceber que lemos um texto " $\mathrm{A}$ " e ao mesmo tempo estamos lendo um texto "B". Barros (2003, p. 30) explica que a intertextualidade é um processo de construção, reprodução ou transformação de sentido. É a incorporação de um texto em outro e este se divide em três processos: citação, alusão e estilização. A citação confirma ou altera o sentido do texto mencionado; a alusão substitui certas figuras (imagem e linguagem) por outras; a estilização é o conjunto de estilos de outros textos.

O plano de expressão é entendido como o meio pelo qual um conteúdo é veiculado. Já o plano de conteúdo é "um conjunto de temas e de figuras que materializa uma dada visão de mundo" (FIORIN, 1988, p. 36). Para Fiorin (2003), o discurso, manifestado por um plano de 
expressão é próprio do plano de conteúdo. Assim, a formação do discurso decorreria do encontro de um plano de conteúdo com um plano de expressão, processo denominado manifestação (FIORIN, 2003, p. 37-38).

Fiorin descreve que o plano de expressão apresenta-se por meio de códigos (verbal, icônico, gestual), e o plano do conteúdo alude ao significado do texto, trata daquilo que o texto diz:

\begin{abstract}
Se alguém ouve ou lê um texto com função utilitária não se importa com o plano de expressão. Ao contrário, atravessa-o e vai diretamente ao conteúdo, para entender a informação. No texto com função estética, a expressão ganha relevância, pois o escritor procura não apenas dizer o mundo, mas recriá-lo nas palavras, de tal sorte que importa não apenas o que se diz, mas o modo como se diz. Como o poeta recria o conteúdo na expressão, a articulação entre os dois planos contribui para a significação global do texto. A compreensão de um texto com função estética exige que se entenda não somente o conteúdo, mas também o significado dos elementos da expressão (FIORIN, 2003, p.78).
\end{abstract}

Segundo o autor, analisar os dois planos de um texto - expressão e conteúdo - torna-se importante, pois possibilita uma visão mais ampla. Analisamos neste trabalho o plano de expressão e do conteúdo dos audiovisuais do BBB com enfoque na observação dos elementos religiosos veiculados pelo programa e apresentados por ambos os planos, obtendo assim uma visão ampliada sobre a intertextualidade presente no reality.

\title{
Elementos religiosos no BBB
}

As análises realizadas neste trabalho se dão por meio dos conceitos de intertextualidade, dialogismo, definições que contribuem para análise dos textos de conteúdo cristão e dos elementos religiosos encontrados no BBB. Para a análise, assistimos 52 episódios da nona temporada do BBB (2009) e selecionamos 15 capítulos. Os elementos encontrados foram trilha sonora, anjo, monstro, quarto branco, confessionário e Grande Irmão.

\section{Trilha Sonora}

Este é o único elemento que é apresentado em todas as edições realizadas até hoje do programa BBB, a música-tema de abertura do reality, intitulada Vida Real, de Paulo Ricardo Medeiros, executada pelo RPM:

[...] Se você soubesse quem você é/ Até onde vai a sua fé/ O que você faria?/ Pagaria pra ver. // Se pudesse escolher/ Entre o bem e o mal, ser ou não ser?/ Se querer é poder/ Tem que ir até o final/ Se quiser vencer [...] (MEDEIROS, 2001) 
Na primeira estrofe, a palavra fé aparece num contexto de interrogação, na segunda pessoa do singular e direcionada de forma direta ao receptor da mensagem. Segundo Paul Tillich (2004, p.224), fé é receber Deus quando Deus se dá a nós, é a aceitação do dom de Deus e da presença da sua graça. A principal justiça é a fé e o mal é a falta dela. Ou seja, a fé é que molda o caráter e esta pode ser a responsável por estabelecer o que fazemos para atingir um determinado objetivo.

A segunda estrofe traz novamente uma pergunta, porém já fornece opções de resposta bem e mal - duas formas utilizadas para classificar algo. Baseado em ensinamentos cristãos e de acordo com um contexto histórico, o bem é tudo aquilo que cria, une, provê, dá suporte e gera. Já o mal está relacionado à destruição, tristeza, miséria, vícios e a morte. Na pergunta: “Entre o bem e o mal, ser ou não ser?”, o telespectador pode responder a pergunta, mesmo que não de forma explicita. Quando se trata de indivíduos, glorificam-se e valorizam-se pessoas que são "boas", enquanto as pessoas que são "ruins" ou, em outras palavras, rebeldes, desordeiras, agitadas, são isoladas do restante da sociedade. O "Bem" e o "Mal" atuam igualmente como agentes de equilíbrio: Deus é a personificação do "Bem Puro" e o Diabo é a personificação do "Mal puro".

\section{Anjo}

A figura do anjo corresponde a de criaturas espirituais, que servem como ajudantes ou mensageiros. O BBB utiliza-se da alusão e menciona o anjo, pois faz referência ao seu plano de conteúdo e expressão: o de expressão por meio do icônico, gestual e verbal; e o de conteúdo por meio do seu significado no texto. No caso do reality, o participante que consegue, através de uma prova, se tornar o anjo da semana tem o direito de salvar alguém da votação. Um exemplo de participante que se tornou anjo no BBB 9 e imunizou um colega foi Max, que concedeu o colar da imunidade para Francine. Pedro Bial pergunta: "Quem você abençoa com o colar da imunidade?", e em seguida Max responde: "Vou abençoar uma pessoa que foi fundamental na minha conquista"7. Conforme mostra a cena abaixo:

\footnotetext{
${ }^{7}$ Disponível em: http://www.youtube.com/watch?v=sbJaMzVTJ_o. Acessado em: 04/02/ 2014.
} 


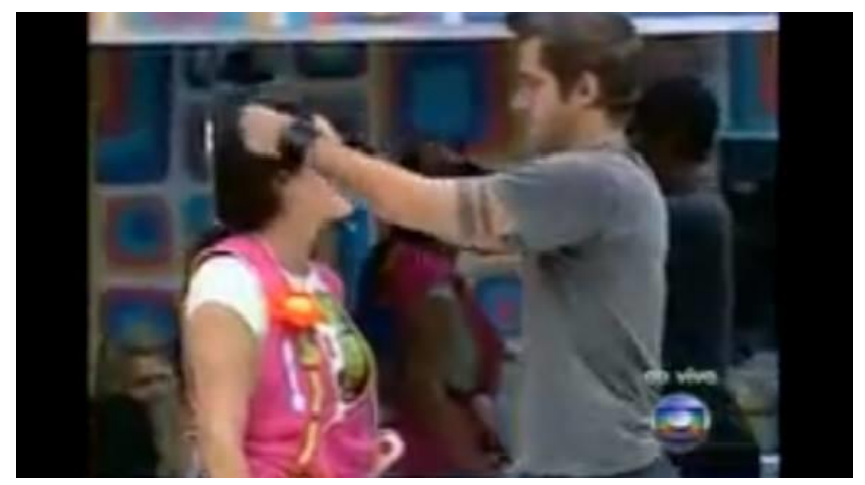

Muitas religiões consideram o anjo como um ser superior, que tem como objetivo intermediar Deus e os seres humanos. Eles são destinados a orientar a vida dos indivíduos. No caso do programa, o anjo é o integrante que tem o poder de imunizar um colega de casa, portanto ter esse poder e delegar essa imunidade a alguém significa a misericórdia ou a salvação. A ilustração abaixo mostra a imagem do anjo retratada por Mauricio Ricardo, responsável pelas ilustrações do reality ${ }^{8}$ :

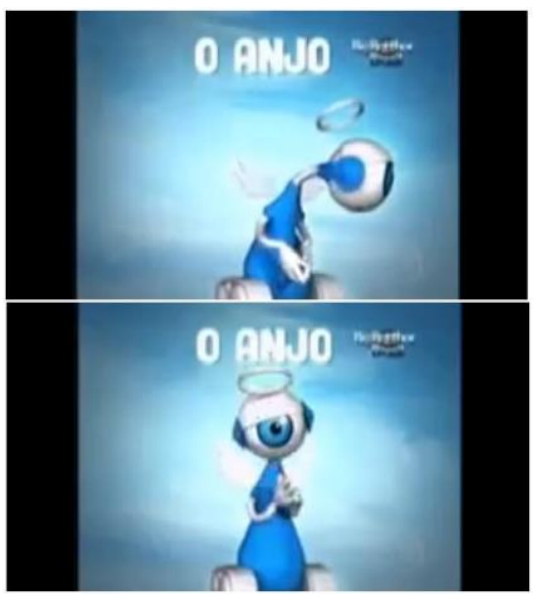

Nesta ilustração, observa-se a utilização predominante da cor azul, significante plástico, definido por Joly como "a interação, que produz o sentido que aprendemos mais ou menos conscientemente a decifrar e que uma observação mais sistemática nos ajuda a compreender melhor" (2007 p. 42). Outra característica do anjo presente na figura é a auréola, "que é definida como certo galardão acidental de felicidade e mérito para além do normal, que se atribui aos santos em virtude do seu especial grau de santidade" (FERREIRA, 2004, p.153). No caso do olho do robô, pode ser feita a ligação com a ideia do olhar onisciente do Grande Irmão (programa), porque pode representar o olhar de Deus, que tudo vê.

A imagem conta ainda com elementos plásticos de acordo com a memória discursiva, que, segundo Patriota e Turton (2004, p. 15), exerce uma função ambígua e faz parte de um

\footnotetext{
${ }^{8}$ Disponível em: http://www.youtube.com/watch?v=380ti4z8oOw\&hd=1. Acessado em: 04/02/ 2014.
} 
processo histórico resultante de um debate de interpretações. Assim, a memória discursiva enfatiza o interdiscurso, porque possibilita dar sentido às nossas palavras, a algo já dito.

Dando continuidade ao plano de expressão, a palavra azul tem origem árabe e persa, lázúrd. Proporciona uma sensação de movimento para o infinito, "céu sem nuvens" (FREITAS, 2007 p. 8). A cor azul, ainda conforme a autora, neste contexto pode estar associada ao céu, à tranquilidade e é um indicativo de plena calma. Portanto, ao associar a cor azul ao conceito de anjo no BBB, observa-se que o participante que é intitulado anjo e recebe o poder da imunidade encontra-se em estado de calmaria, porque poderá proteger um "ente querido".

\section{Monstro}

Quanto ao elemento monstro, o discurso é analisado utilizando-se o entendimento de dialogismo, pois o monstro faz uso da interação de outro texto, que é a perspectiva de diabo para os cristãos. Mais especificamente por meio da alusão, quando ocorre um discurso que utiliza temas ou figuras bases para a compreensão do que foi colocado. O que é possível observar através de características plásticas e do plano de conteúdo.

Em um cenário histórico e com base nos estudos de Nogueira (1986, p.5), a figura do demônio no Ocidente cristão é a encarnação do mal. A imagem de monstro ilustrada no desenho de Mauricio Ricardo, veiculada no programa, representa o personagem com chifres, que pode ser associado à imagem demoníaca da crença religiosa cristã. A ilustração do monstro, além de ter chifres, é predominantemente vermelha. A cor vermelha para Freitas $(2004$, p. 8) pode ser associada a conceitos distintos: guerra, fogo, sangue, perigo ou; força, energia e violência. $\mathrm{O}$ vermelho revela impulso, avidez e força de vontade.

Conforme mostra figura abaixo:

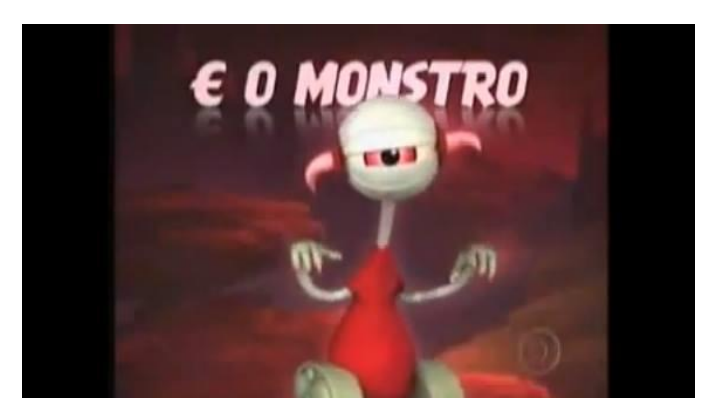

Para relacionarmos a figura do monstro com o sentimento do participante, foram utilizados estudos de Leclercq (1985, p.51), que afirma "que a dor bendita tem um tríplice

\footnotetext{
${ }^{9}$ Disponível em: http://www.youtube.com/watch?v=380ti4z8oOw\&hd=1. Acessado em: 04/02/ 2014. 
caráter: mortificação, penitência e amor". A mortificação desprende, isto é, aceita o sofrimento e aprende a não dar valor ao prazer e isso torna o indivíduo capaz de pensar no bem do próximo. Em seguida, o sofrimento vem como penitência e, por fim, não é o sofrimento que importa, mas sim o amor, afinal a dor só importa como uma prova desse sentimento.

Um exemplo desse tríplice caráter no programa é a participante Priscila cumprindo o castigo atribuído pela figura do monstro, como mostra a figura a seguir ${ }^{10}$ :

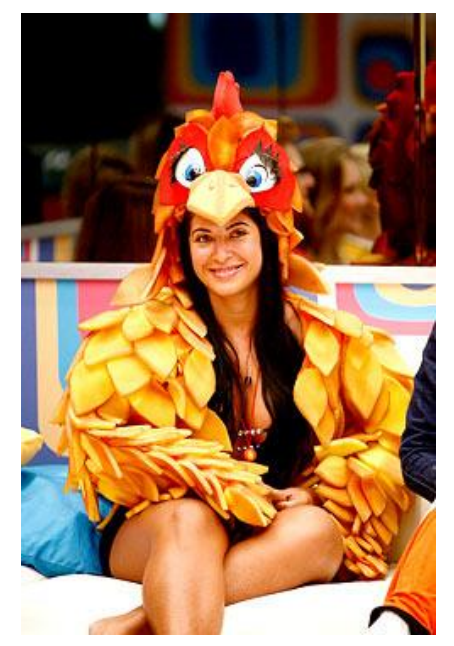

O grande objetivo da realização do castigo é o amor pela realização de um sonho pessoal. No caso da participante Priscila, a permanência no reality show.

\section{Quarto Branco}

Outro elemento religioso presente no BBB, que faz referência ao discurso religioso, e utiliza-se do dialogismo para se comunicar, é o Quarto Branco, local pequeno e totalmente branco, sem janelas ou formas nas paredes, utilizado como forma de punição. As regras do quarto eram: os brothers só poderiam sair para ir ao banheiro e deveriam fazer as refeições no local. Os alimentos eram enviados por meio de uma pequena porta. Caso alguém não resistisse ao castigo, um deles poderia apertar uma sirene e desistir da prova. Porém, ao sair do Quarto branco, o participante seria automaticamente eliminado do BBB 9.

Os participantes Newton, Ralf e Léo foram os brothers que se dirigiram ao quarto, quando Newton atendeu ao Big Fone (telefone que toca em determinados momentos para transmitir mensagens, que na maioria das vezes precisam ser guardadas em sigilo por quem

\footnotetext{
${ }^{10}$ Disponível em: http://bbb.globo.com/BBB9/Noticias/0,,MUL1043144-16397,00PRISCILA+CUMPRE+CASTIGO+DO+MONSTRO.html. Acessado em: 04/02/ 2014.
} 
atendeu). O empresário deveria indicar dois brothers que, junto a ele, participariam de um “castigo". Segundo a tradição cristã, o castigo é uma forma de punição para o indivíduo que não cumpre com suas obrigações e deveres na Terra.

No BBB, os participantes estão cumprindo um castigo, pois não estão totalmente em liberdade e estão restritos às tarefas ditadas pelo programa. Apesar de já estarem confinados desde o início, os participantes e telespectadores associam este ambiente a um local de tortura. ${ }^{11}$

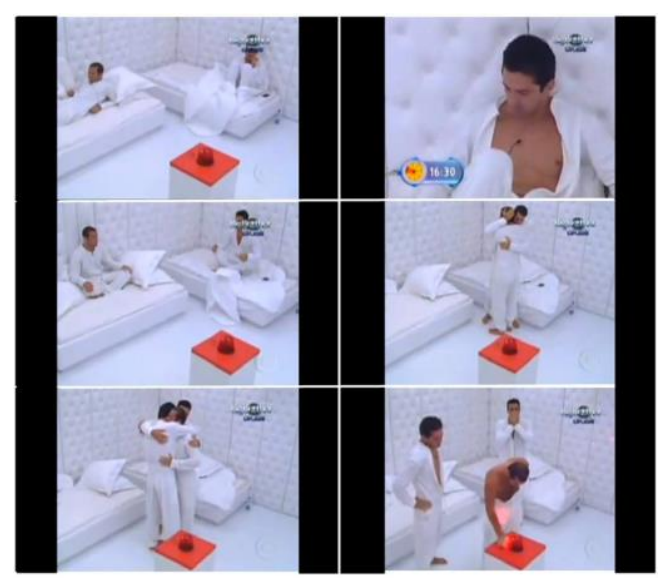

\section{Confessionário}

Este cômodo da casa do reality é o único lugar onde os participantes contam segredos e justificam votos. A conversa entre os brothers e a produção do programa acontece apenas no confessionário, sem a visualização dos telespectadores, por esse motivo é o único local privado. Em um contexto histórico, confessionário na Igreja Católica é um local pequeno e fechado, utilizado para o Sacramento da Confissão. Kilpp (2003, p. 3) descreve que o confessionário é um lugar para esquematizar a confissão individual. Ele faz parte do imaginário cristão, uma vez que o ambiente remete ao mundo católico, um espaço templário. Kilpp (2003, p. 10) descreve funções do confessionário. Uma delas é o voto que os participantes dão uns aos outros para a formação de um paredão; o pedido de clemência (remete-se ao pedido em posições de oração, de súplica) e o aconselhamento, este feito pelos psicólogos e responsáveis pelo programa. Os participantes recebem um feedback de sua performance e são orientados como num confessionário católico.

Para situar o conceito de paredão, é necessário explicar o funcionamento do reality. Toda quinta-feira é o dia de Prova do Líder. O vencedor da prova garante a imunidade para permanecer na casa por mais uma semana, além de um quarto exclusivo e a difícil tarefa de

\footnotetext{
${ }^{11}$ Disponível em: http://www.youtube.com/watch?v=_KG4xrZfF5o. Acessado em: 04/03/2014.
} 
indicar um dos companheiros ao paredão. O paredão, que é formado geralmente aos domingos, é o momento em que o Líder tem para indicar um participante a uma possível eliminação da casa. Em seguida, os outros confinados, inclusive o indicado pelo Líder, vão ao confessionário anunciar seus votos de indicados para a competição do paredão. O voto é individual e pode ser secreto ou não. Em caso de empate, cabe ao líder o voto de Minerva, para finalizar a decisão de quem enfrenta seu indicado para encarar a avaliação do público. A cada semana, da abertura do paredão no domingo até o programa de terça-feira, o público decide qual dos jogadores indicados sairá da casa. A votação é realizada pela internet, por telefone ou por mensagem via celular. $^{12}$

No confessionário católico, o pecador se confessa para o padre dentro de um local reservado na igreja, semelhante aos participantes do programa, que revelam erros e fazem pedidos em dia de paredão. Porém, a confissão é feita ao telespectador. Quando a fala do participante não é transmitida aos telespectadores. Outro sentido do confessionário é o purgatório, ligado aos conceitos de céu e inferno. Segundo a doutrina cristã, imediatamente após a morte, uma pessoa sofre o julgamento em que o destino da alma é especificado. A palavra purgatório sugere o conceito de um local circunscrito, por isso, se aplica, mais comumente à terra, um ambiente destinado à remissão de pecados..$^{13}$

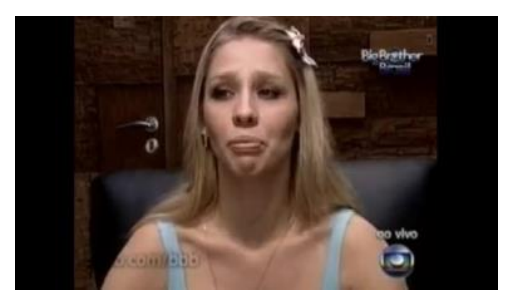

Em sua confissão, Ana Carolina, participante da nona edição, suplica por sua permanência no reality. Ao entrar no confessionário, Pedro Bial diz: “Quando eu disser já, você vai ter 30 segundos para dizer por que você merece ficar na final do Big Brother Brasil. Já!". As palavras da participante foram: "Bom, gente, vocês sabem da minha trajetória aqui. Eesse é meu sétimo paredão, quero pedir muito para vocês me deixarem na casa, para eu ir para a final. Eu sou eu mesma aqui, o tempo todo. Espero que vocês tenham gostado! Eu errei, eu acertei, eu tenho qualidade e tenho os meus defeitos. Isso está muito explícito. Sou inteiramente eu. Por isso eu peço muito o voto de vocês, para me deixarem na casa e me ajudarem a realizar meu sonho de ir para a final e tentar ganhar um milhão de reais”. Na verdade, o confessionário é um

\footnotetext{
${ }^{12}$ Sobre o BBB. Disponível em: http://gshow.globo.com/bbb/bbb14/sobre/o-jogo.html. Acessado em: $18 / 03 / 2014$

${ }^{13}$ Disponível em: http://www.youtube.com/watch?v=Z0m1XhT4S0s. Acessado em: 18/03/2014.
} 
elemento que utiliza da intertextualidade como forma de comunicação, pois os telespectadores necessitam de um conhecimento prévio para compreender o sentido do elemento.

\section{Grande Irmão}

O elemento Grande Irmão pode ser explicado através do conceito de dialogismo, porque carrega consigo marcas de outro texto anterior, no caso, concepção de onipotência e onipresença de Deus. No momento em que o telespectador tem acesso a todas as câmeras e gravações do programa é como se fosse onipresente e onisciente, como uma força maior.

É também uma referência a 1984, de George Orwell, que descreve que a sociedade contemporânea é vigiada todo o tempo por câmeras do governo que controlam os atos de todos os sujeitos. O estado é visto como um Deus, mesmo que suprima a liberdade dos cidadãos. No livro, o governo-vigilante se coloca como o Big Brother, um ser onipotente que vigia a sociedade. Desta forma, fazendo um paralelo com a proposta do programa BBB, o objetivo é tornar normal e cotidiana a invasão de privacidade.

\section{Considerações finais}

Percebemos com as análises dos elementos religiosos que elementos da cultura cristã estão presentes no programa BBB. Na trilha sonora, observamos que é utilizada a ideia de fé, bem e mal. A fé é responsável por instituir o que fazemos para alcançar um objetivo traçado. $\mathrm{O}$ bem e o mal se enquadram num contexto histórico-cristão. $\mathrm{O}$ mal está relacionado à destruição, tristeza e pecado e é o exato oposto do que representa o bem: criar, unir, gerar e dar suporte.

O elemento anjo no BBB dialoga com o anjo do discurso religioso cristão. Para as religiões, o anjo é visto como um ser superior aos seres humanos, e objetiva fazer intermediação entre os seres humanos e Deus. Portanto, a relação entre o anjo do discurso religioso e do reality é a misericórdia ou a salvação.

O monstro faz uso de outro texto: perspectiva de diabo para o discurso religioso. A imagem ilustrativa do monstro no BBB representa um personagem vermelho e com chifres, que se assemelha a uma figura demoníaca da crença cristã.

O Quarto Branco dialoga com uma forma de castigo, que significa pena ou punição e associa-se ao ato de punir e fazer justiça. Percebemos que no texto religioso o castigo é colocado como algo que não traz paz, nem repouso, assim como para os participantes.

No confessionário do BBB, os participantes contam seus segredos e esclarecem seus votos em um local privado. Contextualizando historicamente, para a doutrina cristã, o 
confessionário é um local fechado e de espaço restrito que serve para pedir perdão e suplicar individualmente. No programa, a confissão é feita aos telespectadores e não como no catolicismo, a uma autoridade religiosa.

O conceito de Grande Irmão carrega consigo marcas de outro texto, no caso, a concepção no discurso religioso de onipresença e onipotência de Deus. Quando o telespectador assiste as imagens proporcionadas por todas as câmeras é como se fosse uma força maior (onipresente e onisciente). Não só os telespectadores adquirem esse poder, mas também o reality, que observa os participantes 24 horas por dia. Por fim, uma possível justificativa para a escolha desses elementos religiosos pode ser a busca do BBB por seu público-alvo: pessoas cristãs.

(Artigo enviado em 01/05/2015, aprovado em 03/06/2015)

\section{Referências}

BAKHTIN, M. Marxismo e filosofia da linguagem: problemas fundamentais do método sociológico na ciência da linguagem. 6 ed. São Paulo: Hucitec, 1992.

BAKHTIN, Mikhail. Questões de literatura e de estética: a teoria do romance. 2. ed. São Paulo: Unesp Hucitec, 1990.

BARROS, Diana Luz Pessoa; FIORIN, José Luiz. Dialogismo, polifonia, intertextualidade. São Paulo: Edusp, 2003.

BRAIT, Beth. Bakhtin: conceitos-chave. 4 ed. São Paulo: Contexto, 2007.

BRAIT, Beth et al. Comunicação e Análise do Discurso. São Paulo: Contexto, 2013.

CAMPOS, Lenildo Silveira. Teatro, templo e mercado. Petrópolis: Vozes, 1999.

FIORIN, José Luiz. Introdução ao pensamento de Bakhtin. São Paulo: Ática, 2006. . O regime de 1964: discurso e ideologia. São Paulo: Atual, 1988.

Três questões sobre a relação entre expressão e conteúdo. Disponível em:〈http://seer.fclar.unesp.br/itinerarios/article/viewFile/2673/2379> Acesso em: 03/03/2014, 2003, p.77-89.

FREITAS, Ana Karina Miranda de. Psicodinâmica das cores em comunicação. Disponivel em: <http://www.iar.unicamp.br/lab/luz/ld/Cor/psicodinamica_das_cores_em_ comunicacao.pdf $>$. Acessado em: 14 de março de 2014.

FRESTON, Paul. Protestantismo e política no Brasil. Tese de Doutorado em Ciências Sociais, Campinas: UNICAMP, 1993.

JOLY, Martine. Introdução à análise da imagem. 70 ed. Lisboa: 2007. Digitalizado por SOUZA, R. Disponível em: http://flankus.files.wordpress.com/2009/12/introducao-a-analiseda-imagem-martine-joly.pdf> Acesso em: 03/03/2014.

KILPP, Suzana. O confessionário reality de Big Brother Brasil. Disponível em: $<$ http://www.suzanakilpp.com.br/artigos/O_Confessionario_Reality_de_Big_Brother_Brasil.p df> Acessado em: 22 de abril de 2013. 
KLEIN, Alberto. Imagens de culto e imagens da mídia: Interferências midiáticas no cenário religioso/ Alberto Klein. - Porto Alegre: Sulina, 2006.

KRISTEVA, Julia. Introdução à semanálise. 2 ed. São Paulo: Perspectiva, 2005.

LAZARY, Erika; RODRIGUES, José Carlos. Big Brother no Brasil: Estratégias de comunicação. Curitiba: Editora CRV. 2011.p 13-157.

MARTHE, Marcelo. O Grande Irmão. Revista Veja. Rio de Janeiro, 22 jan. 2003.

PATRIOTA, Karla Regina Macena Pereira; TURTON, Alessandra Navaes. Memória discursiva: sentidos e significações nos discursos religiosos da TV. Disponível em: <http://www.cienciasecognicao.org/revista/index.php/cec/article/view/17/330> Acessado em: 23 de abril de 2013.

PAULINO, Graça; Walty, Ivete; CURY, Maria Zilda. Intertextualidades: teoria e prática. 2ed. Belo Horizonte: Editora Lê,1997.

PINTO, José Milton. Comunicação e discurso: introdução à análise de discursos. 2ed, São Paulo: Conselho Editorial, 2002.

PIETROFORTE, Antônio Vicente. Semiótica Visual: os percursos do olhar. São Paulo: Contexto, 2012.

SANT'ANNA, Affonso Romano de. Paródia, paráfrase e Cia. 8 ed, São Paulo: Ática, 2007.

SODRÉ, Muniz. O triunfo estatístico do banal, 2010. Disponível em:

<http://www.observatoriodaimprensa.com.br/news/imprimir/19472> Acesso em: 10/09/2013.

TILLICH, Paul. História do Pensamento Cristão. $3^{\text {a }}$ edição, São Paulo: Aste, 2004. 